\title{
Assessment and comparison of AFLP and SSR based molecular genetic diversity in Indian isolates of Ascochyta rabiei, a causal agent of Ascochyta blight in chickpea (Cicer arietinum L.)
}

\author{
Rajeev Varshney • Suresh Pande • Seetha Kannan • \\ Thudi Mahendar • Mamta Sharma • Pooran Gaur • \\ Dave Hoisington
}

Received: 7 August 2008 /Revised: 7 December 2008 / Accepted: 19 December 2008

(C) German Mycological Society and Springer-Verlag 2009

\begin{abstract}
Ascochyta blight (AB), caused by Ascochyta rabiei (Pass.) Labr. (anamorph), is the most damaging disease of chickpea (Cicer arietinum L.) and is a serious biotic stress constraint for chickpea production. To understand the molecular diversity in A. rabiei populations of India, a total of 64 isolates collected from AB-infected chickpea plants from different agroclimatic regions in the North Western Plain Zone (NWPZ) of India were analyzed with 11 AFLP (amplified fragment length polymorphism) and 20 SSR (simple sequence repeat) markers. A total of 9 polymorphic AFLP primer pairs provided a total of 317 fragments, of which 130 were polymorphic and showed an average PIC value 0.28. Of the SSR markers, 12 showed polymorphism and provided a total of 29 alleles with an average PIC value 0.35 . To the best of our knowledge, this is the first report on a comparison of AFLP and SSR diversity estimates in A. rabiei populations. The dendrogram developed based on AFLP and SSR data separately, as well as on the combined marker dataset, grouped the majority of $\mathrm{AB}$ isolates as per geographic regions. Model based population structure analysis revealed four distinct populations with varying levels of ancestral admixtures among 64 isolates studied. Interestingly, several AFLP primer combinations and SSR markers showed the locus/ allele specific to $\mathrm{AB}$ isolates of certain regions, e.g., Hisar, Sriganganagar, Gurdaspur, and Sundarnagar. Genetic vari-
\end{abstract}

R. Varshney $(\bowtie) \cdot$ S. Pande $\cdot$ S. Kannan $\cdot$ T. Mahendar $\cdot$

M. Sharma $\cdot$ P. Gaur $\cdot$ D. Hoisington

International Crops Research Institute

for the Semi-Arid Tropics (ICRISAT),

Patancheru 502324 Andhra Pradesh, India

e-mail: r.k.varshney@cgiar.org ability present in $\mathrm{AB}$ isolates of the NWPZ of India suggests the continuous monitoring of changes in A. rabiei population to anticipate the breakdown of $\mathrm{AB}$ resistance in chickpea cultivars grown in India.

Keywords Ascochyta blight $\cdot$ Resistance $\cdot$ Molecular diversity $\cdot$ SSR $\cdot$ AFLP

\section{Introduction}

Ascochyta blight (AB) caused by Ascochyta rabiei (Pass.) Labr. (anamorph), is the most damaging disease of chickpea (Cicer arietinum L.) causing yield losses of up to $100 \%$ and having a global distribution (Pande et al. 2005). In the North Western Plain Zone (NWPZ) of India, AB is a serious production constraint of chickpea grown in postrainy season and the disease often turns epidemic (Nene 1984). As a result, there is a drastic reduction in area and productivity of chickpea, and most of the rice fallows where chickpea is grown traditionally are sown with other crops or left fallow during the post-rainy season. To reestablish/revive chickpea production in these areas, use of resistant varieties is the most practical approach as it is effective, economical, and environmentally friendly (Singh and Reddy 1996). However, high levels of disease resistance are scarce in chickpea germplasm with a desirable agronomic background. Breeding of chickpeas for resistance to $\mathrm{AB}$ is, however, complicated by the frequent breakdown of host plant resistance, probably because of the variable nature of the pathogen (Singh and Reddy 1991). Therefore, it is imperative to study the variation among $A$. rabiei isolates in order to identify stable 
and durable sources of resistance against the prevalent pathotypes of $A$. rabiei that exist in the target regions.

Previous studies have revealed high levels of pathogenic and genetic variation in A. rabiei (reviewed by Pande et al. 2005). A high level of pathogenic variability has also been reported in the $\mathrm{AB}$ isolates from India (Ambardar and Singh 1996; Basandrai et al. 2005). A technique that could be used to rapidly characterize $A$. rabiei population in a particular area would provide important information for $\mathrm{AB}$ management and resistance breeding. However, evaluating genetic diversity in field requires powerful discriminating, selectively neutral and reliable, criteria for genotyping the isolates (e.g., see Gowen et al. 1989). In order to measure genetic variability more precisely, molecular markers provide an unbiased estimate of total genomic variation and have the potential to minimize errors due to sampling variance (Spooner et al. 1996). Furthermore, determination of fungal genetic diversity based on molecular markers is reliable as it is independent of culture conditions.

In plant and animal systems, a variety of molecular markers are available and have been used for different type of applications. However, for assessment of fungal genetic diversity, random DNA-based markers have been used in the majority of cases. The most commonly used DNAbased markers for assaying genomic variation in fungal species include randomly amplified polymorphic DNA (RAPD; Williams et al. 1990) and amplified fragment length polymorphism (AFLP; Vos et al. 1995). These markers are PCR-based markers and do not need any sequence information but provide several genomic fragments with a marker in the single experiment (see Varshney et al. 2007). However, these markers are not locus specific and RAPDs suffer with reproducibility. Simple sequence repeat (SSR) markers on the other hand represent the locus specific and co-dominant marker systems which have been proved the markers of choice in plant genetics and breeding applications (Gupta and Varshney 2000). Generation of SSR markers is a time consuming, labour intensive and expensive task; only a few fungi enjoy the availability of SSR markers. In case of Ascochyta rabiei, a set of 20 SSR markers was developed by Geistlinger et al. (2000).

Only a few molecular genetic studies have been conducted to assess the diversity in $\mathrm{AB}$ isolates in different parts of world by using SSR-based oligo-fingerprinting (Weising et al. 1991; Morjane et al. 1994; Geistlinger et al. 1997; Udupa et al. 1998; Jamil et al. 2000; Barve et al. 2004), AFLP (Peever et al. 2004), RAPD (Santra et al. 2001; Chongo et al. 2004), and SSRs (Geistlinger et al. 2000). In some studies, comparative assessment of genetic diversity, based on different marker systems, i.e., oligo-fingerprinting, RAPDs, and AFLPs, has been carried out (Udupa et al. 1998; Peever et al. 2004). However, little is known about the level of genetic diversity of this pathogen in the NWPZ of
India, where $\mathrm{AB}$ is a serious constraint of chickpea and the disease turns epidemic. Genetic diversity information in addition to pathogenic variability may be useful in developing chickpea varieties with resistance to $\mathrm{AB}$. The present study, therefore, was undertaken to assess the extent of genetic diversity of A. rabiei isolates of the NWPZ of India using AFLP and SSR markers. Further, the potential of two marker systems for assessing the genetic variability of isolates has been compared.

\section{Materials and methods}

Fungal isolates

A total of 64 isolates from 16 cultures (four isolates from each culture) of $A$. rabiei were isolated (Punithalingam and Holliday 1972) from AB-infected chickpea plants collected from different agroclimatic regions in NWPZ including foothills, low hills, sub-tropical and sub-mountain zones of the Himalayas in India (Table 1). Four single spore isolates of individual cultures were maintained on chickpea dextrose agar (CDA, kabuli chickpea seed meal $40 \mathrm{~g}$, dextrose $20 \mathrm{~g}$ and agar $20 \mathrm{~g} / 1$ distilled water) at $4^{\circ} \mathrm{C}$.

\section{DNA isolation}

Genomic DNA from the fungal mycelium was extracted by the CTAB method as suggested in Cuc et al. (2008) except that $\beta$-Mercaptoethanol was absent in the extraction buffer.

\section{AFLP analysis}

AFLP analysis was carried out using the commercial kit of Life Technologies (USA) as per the manufacturer's protocols with slight modifications as described below. Fungal genomic DNA (400 ng) was digested with the two restriction endonucleases, EcoRI and $M s e \mathrm{I}$, at $37^{\circ} \mathrm{C}$ for $2 \mathrm{~h}$ and heated at $70^{\circ} \mathrm{C}$ for $15 \mathrm{~min}$ to inactivate the enzyme. The DNA fragments were ligated to EcoRI and MseI adapters at $20^{\circ} \mathrm{C}$ for $2 \mathrm{~h}$ and, after terminating the reaction, the ligation mixture was diluted 10-fold with TE buffer and the fragments were preamplified in a thermal cycler (MJ Research, USA) using a temperature cycle of $94^{\circ} \mathrm{C}$ for $30 \mathrm{~s}$, $56^{\circ} \mathrm{C}$ for $60 \mathrm{~s}$, and $72^{\circ} \mathrm{C}$ for $60 \mathrm{~s}$ in a total of 30 cycles. Selective amplification was carried out using the primers provided in the kit according to the manufacturer's protocol. Four EcoRI primer (E-AC, E-AG, E-TC and ETG) and eight MseI (M-CAA, M-CAT, M-CAC, M-CAG, M-CTA, M-CTT, M-CTG and M-CTC) primers were used in 11 combinations (E-AC/M-CTG, E-AC/M-CTC, E-AC/ M-CTT, E-AG/M-CTA, E-AG/M-CTC, E-TC/M-CAA, ETC/M-CAC, E-TC/M-CAG, E-TC/M-CAT, E-TG/M-CTG, 
Table 1 Sixty-four Ascochyta rabiei isolates selected for molecular diversity analysis

\begin{tabular}{lllll}
\hline S No. & Culture ID & Site of collection & State of collection & Isolate names used in dendrogram \\
\hline 1 & AB1 & Gurdaspur & Punjab & AB1_GUR_1, AB1_GUR_2, AB1_GUR_3, AB1_GUR_4 \\
2 & AB3 & Ambala & Haryana & AB3_AMB_1, AB3_AMB_2, AB3_AMB_3, AB3_AMB_4 \\
3 & AB4 & Hisar & Haryana & AB4_HIS_1, AB4_HIS_2, AB4_HIS_3, AB4_HIS_4 \\
4 & AB6-02 & Dhaulakuan & Himachal Pradesh & AB6_DHA_1, AB6_DHA_2, AB6_DHA_3, AB6_DHA_4 \\
5 & AB7-03 & Pantnagar & Uttaranchal & AB7_PAN_1, AB7_PAN_2, AB7_PAN_3, AB7_PAN_4 \\
6 & AB8-03 & Palampur & Himachal Pradesh & AB8_PAL_1, AB8_PAL_2, AB8_PAL_3, AB8_PAL_4 \\
7 & AB11-03 & Ropar & Punjab & AB11_ROP_1, AB11_ROP_2, AB11_ROP_3, AB11_ROP_4 \\
8 & AB12-03 & Abohar & Punjab & AB12_ABO_1, AB12_ABO_2, AB12_ABO_3, AB12_ABO_4 \\
9 & AB13-03 & Gurdaspur & Punjab & AB13_GUR_1, AB13_GUR_2, AB13_GUR_3, AB13_GUR_4 \\
10 & AB14-03 & Sundernagar & Himachal Pradesh & AB14_SUN_1, AB14_SUN_2, AB14_SUN_3, AB14_SUN_4 \\
11 & AB15-03 & Berthin & Himachal Pradesh & AB15_BER_1, AB15_BER_2, AB15_BER_3, AB15_BER_4 \\
12 & AB16 & Palampur & Himachal Pradesh & AB16_PAL_1, AB16_PAL_2, AB16_PAL_3, AB16_PAL_4 \\
13 & AB17-02 & Ludhiana & Punjab & AB17_PUN_1, AB17_PUN_2, AB17_PUN_3, AB17_PUN_4 \\
14 & AB18-03 & Hisar & Haryana & AB18_HIS_1, AB18_HIS_2, AB18_HIS_3, AB18_HIS_4 \\
15 & AB26 & Sriganganagar & Rajasthan & AB26_GAN_1, AB26_GAN_2, AB26_GAN_3, AB26_GAN_4 \\
16 & AB27 & Sriganganagar & Rajasthan & AB27_GAN_1, AB27_GAN_2, AB27_GAN_3, AB27_GAN_4 \\
\hline
\end{tabular}

and E-TA/M-CAT). The EcoRI primer for each combination was labeled with $\left[\gamma_{-}{ }^{32} \mathrm{P}\right]$-ATP $(3000 \mathrm{Ci} / \mathrm{mmol})$ and the DNA amplification was carried out as per the manufacturer's protocol. The PCR products in 5.0- $\mu$ l sub-samples were separated by electrophoresis on $6 \%$ denaturing polyacrylamide DNA sequencing gel containing $7.5 \mathrm{M}$ urea. Autoradiograms were obtained using Kodak X-Omat film.

\section{SSR analysis}

A set of 20 SSR markers $(A r \mathrm{~A} 02 \mathrm{~T}, \operatorname{ArA03T}, \operatorname{ArA06\mathrm {T}}$, ArA08T, $A r \mathrm{~A} 11 \mathrm{~T}, A r \mathrm{R} 08 \mathrm{~T}, A r \mathrm{R} 10 \mathrm{~T}, A r \mathrm{H} 02 \mathrm{~T}, A r \mathrm{H} 04 \mathrm{~T}$, $A r \mathrm{H} 05 \mathrm{~T}, A r \mathrm{H} 06 \mathrm{~T}, A r \mathrm{~S} 03 \mathrm{~T}, A r \mathrm{R} 01 \mathrm{D}, A r \mathrm{R} 04 \mathrm{D}, A r \mathrm{R} 12 \mathrm{D}$, $A r \mathrm{R} 02 \mathrm{D}, A r \mathrm{H} 02 \mathrm{D}, A r \mathrm{H} 07 \mathrm{D}, A r \mathrm{R} 08 \mathrm{D}$ and $A r \mathrm{H} 11 \mathrm{D})$, described in Geistlinger et al. (2000) were used for analyzing the SSR diversity. For SSR analysis, $10 \mathrm{ng}$ DNA from each isolate was used with the SSR primer pairs. PCR reaction was performed in $5-\mu 1$ volumes containing $10 \mathrm{ng}$ of template DNA, $16 \mathrm{mM}\left(\mathrm{NH}_{4}\right)_{2} \mathrm{SO}_{4}, 67 \mathrm{mM}$ Tris$\mathrm{HCl}$ (pH 8.8), 0.01\% Tween-20, $1.6 \mathrm{mM} \mathrm{MgCl} 2,0.2 \mathrm{mM}$ dNTP's, $0.6 \mu \mathrm{M}$ of each primer and 0.05 units Taq DNA polymerase (Bioline, UK). After initial denaturation $\left(95^{\circ} \mathrm{C}\right.$, $20 \mathrm{~s})$, PCR was run for 35 cycles $\left(94^{\circ} \mathrm{C}\right.$ for $20 \mathrm{~s}, 53^{\circ} \mathrm{C}$ for $25 \mathrm{~s}, 67^{\circ} \mathrm{C}$ for $23 \mathrm{~s}$ ) in a MJ Research PTC 200 thermocycler. PCR products were separated on $6 \%$ polyacrylamide gels and visualized by using silver staining protocol (Tegelstrom 1992).

Molecular diversity analyses

AFLP fragments visualized on the autoradiogram were scored as the presence (1) or absence ( 0 ) of a band, and the level of polymorphism was expressed as a percentage based on the number of polymorphic bands obtained from the total number of fragments amplified with a marker. In the case of SSR experiments, presence or absence of the allele at a given locus, visualized by silver staining, was scored as 1 and 0 .

The polymorphism information content (PIC) values measure the informativeness of a given DNA marker. The PIC value for each AFLP primer combination was calculated as proposed by Roldan-Ruiz et al. (2000):

$\mathrm{PIC}_{i}=2 f_{i}\left(1-f_{i}\right)$,

where $\mathrm{PIC}_{i}$ is the polymorphic information content of marker $i, f_{i}$ the frequency of the marker bands which were present and $1-f_{i}$ the frequency of marker bands which were absent. PIC was averaged over the bands for each primer combination.

In the case of SSR markers, the PIC value of SSR loci was measured as given by Anderson et al. (1993):

$\mathrm{PIC}=1-\sum_{\mathrm{i}=1}^{\mathrm{k}} P_{i}^{2}$

where $\mathrm{k}$ is the total number of alleles detected for a given marker locus and $P_{i}$ is the frequency of the $i$ th allele in the set of genotypes investigated.

The average number of DNA fragments amplified/ detected per genotype using a marker system is considered as Multiplex Ratio ( $n$ ).

In case of AFLP, however, many loci (fragments or bands) are non-polymorphic in the germplasm of interest. The number of loci polymorphic in the isolates, analyzed per experiment, called Effective multiplex ratio $(E)$, is estimated as per Powell et al. (1996):

$E=n \times \beta$ 
where $\beta$ is the fraction of polymorphic markers and is estimated after considering the polymorphic loci $\left(n_{p}\right)$ and non-polymorphic loci $\left(n_{n p}\right)$ as $\beta=n_{p} /\left(n_{p}+n_{n p}\right)$.

\section{Cluster analysis}

The 0/1 matrix of the markers was used for the calculation of genetic similarity according to Nei (1972). Further, an UPGMA (Unweighted Pair Group Method Arithmetic Average) dendrogram was constructed using PAUP 4.0 (Swofford 1998) and Dendroscope (Huson et al. 2007)

\section{Population structure analysis}

A Bayesian clustering analysis was undertaken using the program STRUCTURE (Pritchard et al. 2000). This method uses multilocus genotypes to infer the fraction of an accession's genetic ancestry that belongs to a population for a given number of populations $(K)$. The posterior probabilities were estimated using a Markov chain Monte Carlo method (MCMC). The results were based on 100,000 iterations of this chain, following a burn-in period of 100,000 iterations. The MCMC chain was run multiple times, using a correlated allele frequency model (prior mean $=0.01$, prior SD $=0.05$ and Lambda $=1.0$ in the advance option of the STRUCTURE program.

\section{Results}

To understand the diversity pattern among $\mathrm{AB}$ isolates, two markers systems, AFLPs and SSRs, were employed. The molecular diversity data based on AFLP and SSR markers were compared with each other and genetic variability was assessed among $\mathrm{AB}$ isolates.
AFLP- based genetic diversity

A total of 11 AFLP primer combinations involving five EcoRI and 9 MseI primers were used for genetic analysis of $\mathrm{AB}$ isolates (Table 2). Two primer combinations, namely E-AC/ M-CTC and E-TA/M-CAT, showed no polymorphism. The remaining 9 primer combinations yielded from 7 to 70 fragments with an average of 30.1 fragments per primer combination. Effective multiplex ratio for these primer combinations ranged from 1 (E-AC/M-CTT, E-AG/M-CTA, E-TG/M-CTG) to 42 (E-AG/M-CTC) with an average of 14.44. In total, 317 fragments were amplified by 11 primer combinations across $64 \mathrm{AB}$ isolates. However, only 130 fragments (41\%), generated by 9 primer combinations, displayed polymorphism. The polymorphic fragments ranged from 5\% (E-AC/M-CTT) to $83 \%$ (E-AC/M-CTG) fragments with an average of $34.5 \%$ fragments per primer combination (Table 2). The PIC value of the polymorphic fragments varied from 0.03 to 0.50 across the isolated for AFLP primer combinations examined (data not shown). The PIC value for individual primer combination was in the range of 0.16 (EAG/M-CTA, E-TC/M-CAT and E-TC/M-CAG) to 0.39 (E$\mathrm{TC} / \mathrm{M}-\mathrm{CAC}$ ) with an average of 0.28 per primer combination.

\section{SSR-based genetic diversity}

For assaying the allelic diversity, a total of 20 SSR markers were used. However, only $12(60 \%)$ SSR markers showed polymorphism among $\mathrm{AB}$ isolates (Table 3 ). The remaining 8 (40\%) markers (ArA03T, ArA11T, ArR08T, ArR10T, $A r \mathrm{R} 01 \mathrm{D}, A r \mathrm{~A} 02 \mathrm{D}, A r \mathrm{H} 02 \mathrm{D}$ and $A r \mathrm{~A} 04 \mathrm{~T})$ were found monomorphic in the $\mathrm{AB}$ isolates of the present study. The polymorphic SSR marker in the present study showed 2-4 alleles with an average of 2.42 alleles per locus. The PIC value varied from 0.30 to 0.49 with an average of 0.35 per marker (Table 3).
Table 2 Diversity features of AFLP

\begin{tabular}{llllll}
\hline $\begin{array}{l}\text { Primer } \\
\text { combination }\end{array}$ & $\begin{array}{l}\text { Total no. of } \\
\text { bands }\end{array}$ & $\begin{array}{l}\text { No. of polymorphic } \\
\text { bands }\end{array}$ & $\begin{array}{l}\% \\
\text { Polymorphism }\end{array}$ & $\begin{array}{l}\text { Effective } \\
\text { multiplex ratio }\end{array}$ & $\begin{array}{l}\text { PIC } \\
\text { value }\end{array}$ \\
\hline E-AC/M-CTG & 24 & 20 & 83 & 20 & 0.21 \\
E-AC/M-CTT & 19 & 1 & 5 & 1 & 0.39 \\
E-AG/M-CTA & 17 & 1 & 6 & 1 & 0.30 \\
E-AG/M-CTC & 57 & 42 & 74 & 42 & 0.29 \\
E-TC/M-CAA & 70 & 40 & 57 & 40 & 0.28 \\
E-TC/M-CAC & 27 & 5 & 19 & 5 & 0.27 \\
E-TC/M-CAG & 22 & 2 & 9 & 2 & 0.30 \\
E-TC/M-CAT & 34 & 18 & 53 & 18 & 0.16 \\
E-TG/M-CTG & 24 & 1 & 4 & 1 & 0.30 \\
Average & 32.66 & 14.44 & 34.44 & 14.44 & 0.28 \\
\hline
\end{tabular}


Table 3 SSR diversity in pathogen isolates

\begin{tabular}{|c|c|c|c|}
\hline $\begin{array}{l}\text { Marker } \\
\text { name }\end{array}$ & $\begin{array}{l}\text { Amplicon size } \\
\text { range (bp) }\end{array}$ & $\begin{array}{l}\text { Number of } \\
\text { alleles }\end{array}$ & $\begin{array}{l}\text { PIC } \\
\text { value }\end{array}$ \\
\hline $\operatorname{ArA02T}$ & 150 & 2 & 0.30 \\
\hline$A r \mathrm{~A} 06 \mathrm{~T}$ & 140 & 2 & 0.30 \\
\hline $\operatorname{ArA08T}$ & 220 & 2 & 0.30 \\
\hline ArH02T & 340 & 4 & 0.49 \\
\hline$A r \mathrm{H} 04 \mathrm{~T}$ & 210 & 2 & 0.30 \\
\hline ArS03T & 210 & 2 & 0.30 \\
\hline ArH05T & 200 & 3 & 0.44 \\
\hline ArH06T & 190 & 3 & 0.49 \\
\hline $\operatorname{ArR} 12 \mathrm{D}$ & 200 & 2 & 0.31 \\
\hline$A r \mathrm{H} 08 \mathrm{D}$ & 180 & 2 & 0.30 \\
\hline$A r \mathrm{H} 07 \mathrm{D}$ & 190 & 3 & 0.35 \\
\hline$A r \mathrm{H} 11 \mathrm{D}$ & 170 & 2 & 0.30 \\
\hline Average & 200 & 2.42 & 0.35 \\
\hline
\end{tabular}

Comparison of AFLP and SSR markers

As $\mathrm{AB}$ isolates were characterized using AFLP and SSR markers, an attempt was made to compare the utility of these two marker systems for assessment of diversity of $\mathrm{AB}$ isolates. While 11 AFLP primer combinations provided the 317 fragments, the 20 SSR markers yielded 20 loci. Thus a higher multiplex ratio (14.44) was observed for AFLP markers as compared to SSR markers (1.0). PIC values were, however, higher for SSR markers (average 0.35) as compared to AFLP markers (0.28).

\section{Genetic variability among isolates}

As allelic diversity data were obtained for SSR and AFLP markers, these genotyping data were used to construct UPGMA dendrogram separately. All $64 \mathrm{AB}$ isolates were grouped into six groups based on SSR data (Fig. 1). Group I contained isolates from Berthin, Sriganganagar, Palampur, Ambala, Dhaulakuan, and Ludhiana, group II contained isolates from Ropar and Abohar and group VI included the isolates from Hisar and Sriganganagar. The other three groups showed grouping of region-specific isolates. For instance, all the isolates from Gurdaspur were present in group III, the isolates from Sundarnagar were present in group IV. However, group V had two isolates from Ambala while the other two isolates of Ambala were present in group I.

The AFLP-based dendrogram showed higher resolution in grouping isolates into different groups (Fig. 2). Primarily, four groups were observed in this dendrogram which could be further grouped into eight subgroups. Almost all these subgroups (except Gr III) contained the isolates of the same geographical location. Nevertheless one isolate each from Ambala, Ropar, Sriganganagar, and Abohar regions (AB3_AMB_4, AB11_ROP_4, AB26_GAN_4 and
AB12_ABO_1) were entirely separated from the other isolates.

In the dendrogram based on combined SSR and AFLP markers (Fig. 3), the isolates could be grouped into five major groups which could be further subdivided into a total of ten subgroups. The majority of the subgroups, as in the case of the AFLP-based dendrogram, contained regionspecific isolates. However, there were also some exceptions. For instance, two isolates from Ambala (AB3_AMB_1 and AB3_AMB_3) could not be grouped closely with the remaining isolates of Ambala (AB3_AMB2 and AB3_AMB_4). It seems that these isolates are quite diverse compared with other isolates. Indeed, both these isolates also showed a similar diverse pattern compared with other isolates in the SSR and AFLP dendrograms.

\section{Genetic structure of $\mathrm{AB}$ isolates}

On analysis of $64 \mathrm{AB}$ isolates for population structure using a model-based approach (Pritchard et al. 2000), we identified four genetically distinct groups or admixtures thereof within the $\mathrm{AB}$ isolates studied. The estimated likelihood values were variable among different runs $(\mathrm{K}=$ $2--)$, so we chose $\mathrm{K}=4$ for final analysis as the $\log$ likelihood function was found to increase up to $\mathrm{K}=4$ and deto crease thereafter. Group 3 was the largest with 21 $(32.8 \%)$ isolates representing 5 different states (dark shade in Fig. 4). Group 1 was represented by 12 isolates which include 4 from Rajasthan and 8 from Haryana (medium dark shade in Fig. 4) and group 2 contained 12 isolates from Punjab and 4 from Himachal Pradesh (light dark shade in Fig. 4). Of $15 \mathrm{AB}$ isolates grouped in group 4 (white in Fig. 4), 53.3\% were from Punjab, 26.7\% from Himachal Pradesh and 20\% were from Rajasthan.

\section{Discussion}

In the past, several studies for assessing molecular diversity in $\mathrm{AB}$ isolates were conducted using RAPD markers that showed polymorphism with $12.9-28.9 \%$ primers (Udupa et al. 1998; Santra et al. 2001; Chongo et al. 2004). Furthermore, about 10 fragments per primer were obtained in these studies. Therefore, compared to RAPD markers, AFLP markers are more informative as a higher percentage of primers $(81.8 \%)$ as well as a higher number of fragments (ca. 30) per primer pairs have been reported in the present study.

Although an SSR-based oligonucleotide fingerprinting approach has been used in several studies to assess the molecular diversity in AB isolates (Weising et al. 1991; Morjane et al. 1994; Geistlinger et al. 1997; Udupa et al. 1998), the sequence tagged microsatellite (STMS)-based 


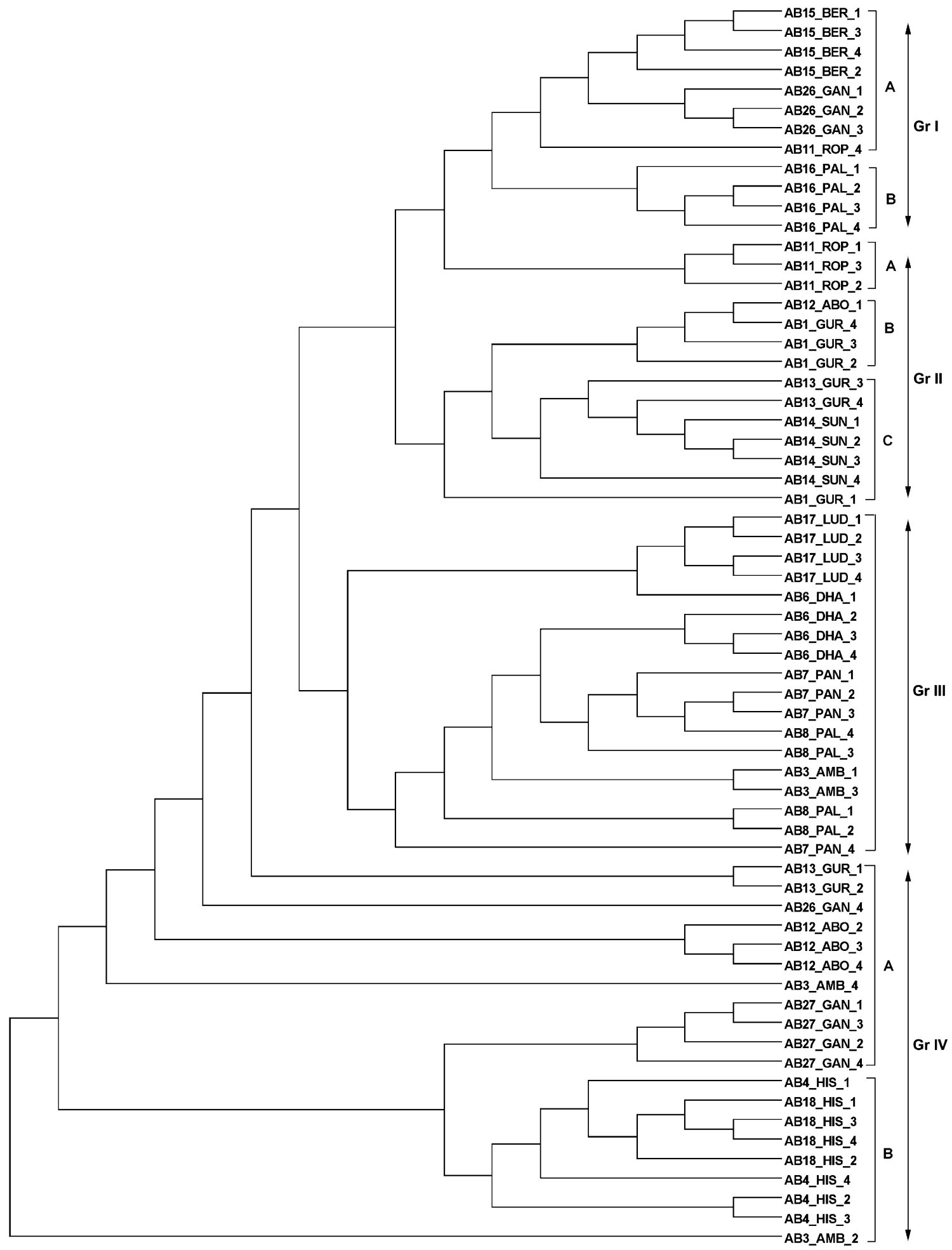

Fig. 1 Grouping of Ascochyta rabiei isolates based on genotyping data for 12 SSR markers

SSR analysis has only been done in few studies (e.g., Geistlinger et al. 2000; Barve et al. 2004). STMS-based SSR markers have been proven very useful in plant genetic and breeding because of being co-dominant, multi-allelic, and locus-specific in nature (Gupta and Varshney 2000).
These reasons led to the development of a set of STMSbased SSR markers for A. rabei (Geistlinger et al. 2000), and these have been used for assaying the molecular diversity in $\mathrm{AB}$ isolates in the present study. The polymorphic SSR marker in the present study showed 2-4 


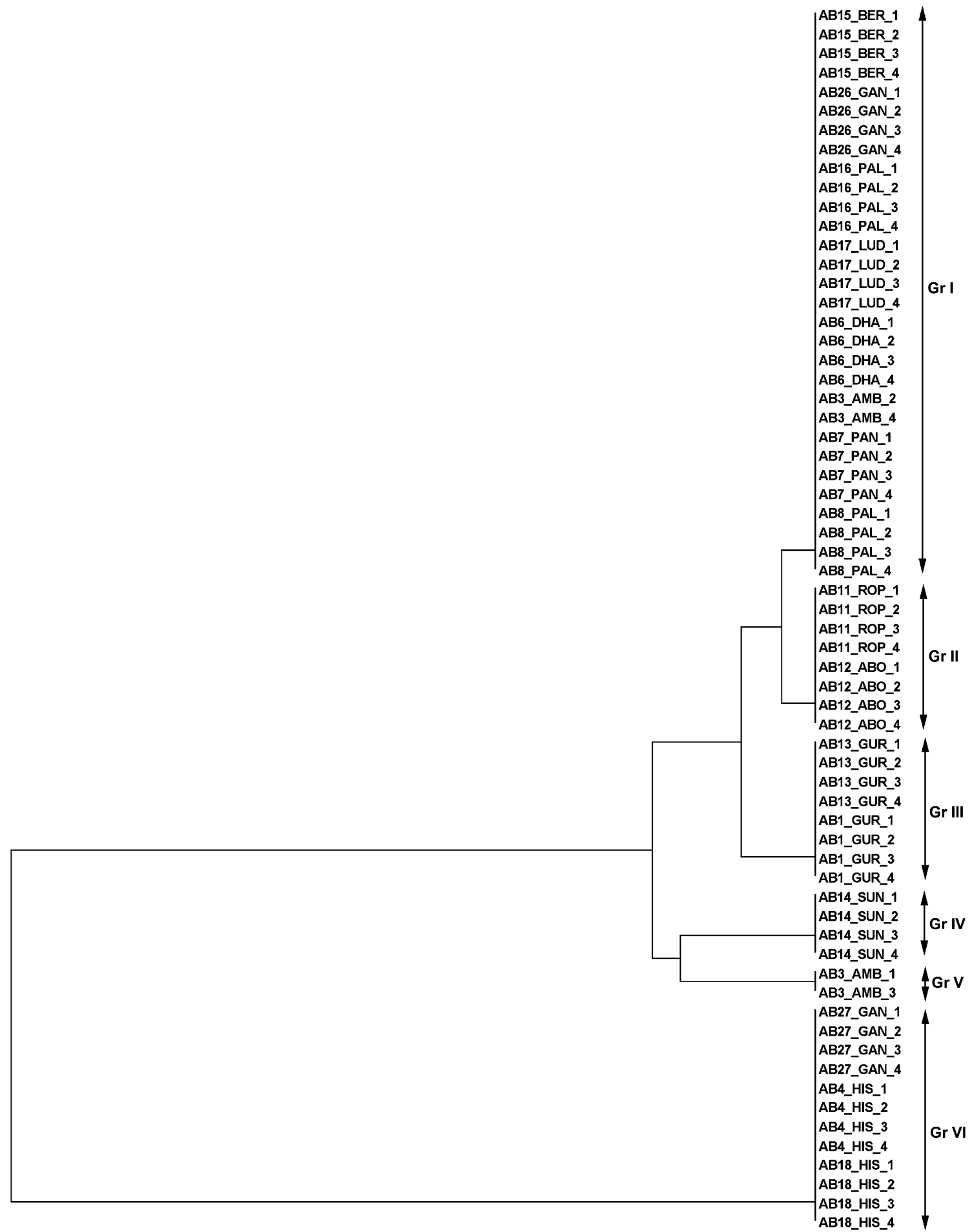

Fig. 2 Grouping of Ascochyta rabiei isolates based on genotyping data generated by nine AFLP primer pairs

alleles with an average of 2.42 alleles per locus. In contrast to the present study, Barve et al. (2004) reported up to 15 alleles at one SSR locus. It is noteworthy here that Barve et al. (2004) analyzed a larger collection of AB isolates (37 isolates from India and 38 isolates from 15 other countries) at a highly polymorphic SSR locus (ARMS1) known for the A. rabiei genome. Similarly, Geistlinger et al. (2000) reported up to 14 alleles per locus among 22 isolates representing the worldwide collection of $\mathrm{AB}$ isolates. However, 3.8 alleles per locus were reported among 52 isolates representing a "new world" collection of $\mathrm{AB}$ isolates (Phan et al. 2003). The PIC value of the polymorphic SSR markers, in the present study, varied from 0.30 to 0.49 with an average of 0.35 per marker 


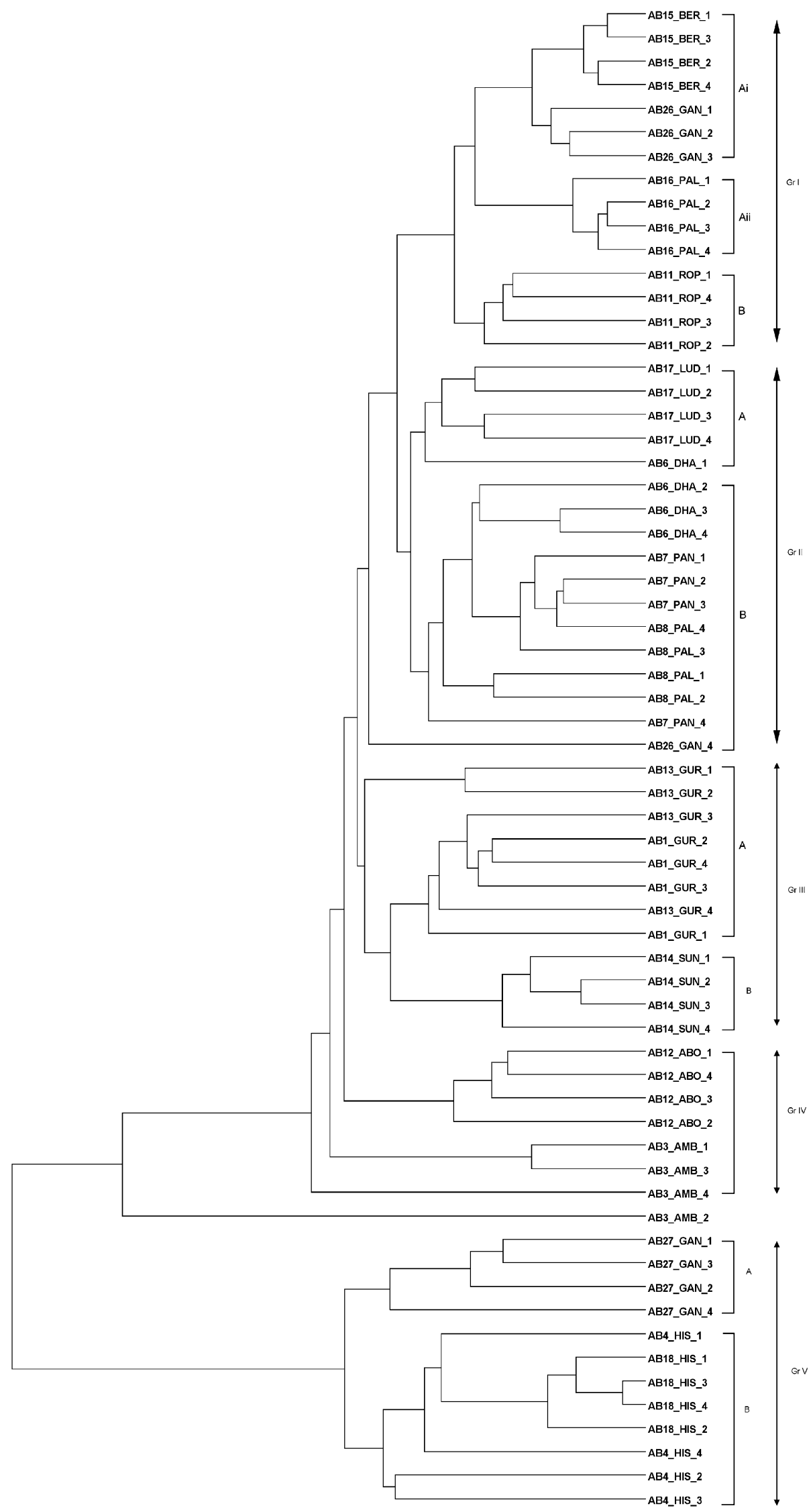

Fig. 3 Grouping of Ascochyta rabiei isolates based on combined SSR and AFLP marker dataset 
Fig. 4 Ancestries of 64 isolates estimated from 317 AFLP loci and 20 SSR loci using STRUCTURE (Pritchard et al. 2000). Four different shades of black and white colors represent four subpopulations (or groups) in Aschochyta rabiei isolates

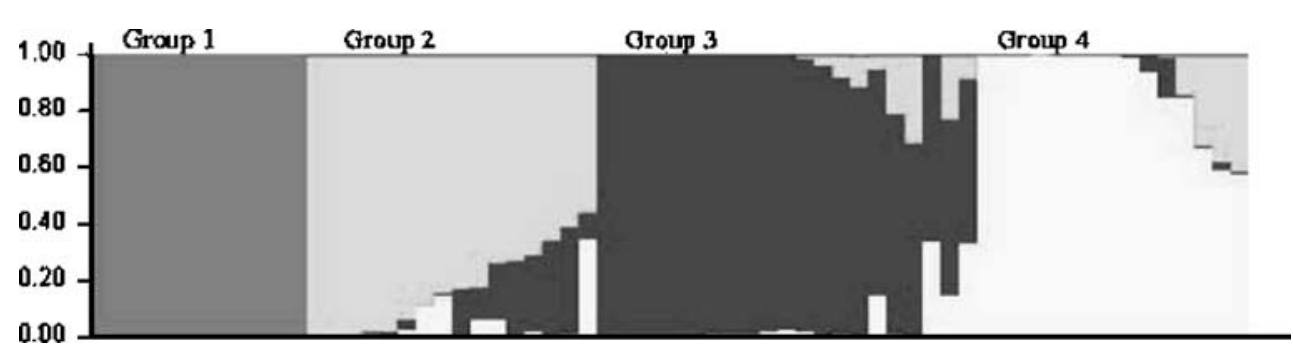

(Table 3). Like the PIC value, the genetic similarity index $\left(H_{E}\right)$ was calculated by Geistlinger et al. (2000) among 22 $\mathrm{AB}$ isolates of worldwide collection and it varied from 0.17 to 0.90 with an average 0.47 per marker. The higher genetic diversity value of the SSR markers as compared to the PIC value of the present study can be attributed to the diverse nature of $\mathrm{AB}$ isolates analyzed in the study of Geistlinger et al. (2000).

The higher number of loci per primer combination is the feature of AFLP that provides the higher effective multiplex ratio (EMR) to AFLP (14.44) as compared to SSR markers (1.0). Since AFLP represents a dominant marker system, the AFLP fragments were bi-allelic and SSR loci, due to co-dominance in nature, were detected on an average 2.42 alleles (Gupta and Varshney 2000). The PIC value for SSR markers $(0.35)$ was also higher as compared to AFLP primer pairs $(0.33)$.

While searching the literature, no report was available on the information of the PIC value for AFLP primer pairs used for diversity assessment of $\mathrm{AB}$ isolates. Nevertheless, the reported PIC values for different AFLP primer pairs may be useful for selecting comparatively more informative markers in future for assessment of molecular diversity of $\mathrm{AB}$ isolates of India or other geographic regions.

In terms of comparative marker polymorphism, AFLP markers showed $81.8 \%$ polymorphic fragments as compared to $60 \%$ polymorphism detected by SSR markers. Because of higher EMR and assaying the genome wide polymorphism, AFLP marker system is perhaps better as compared to SSRs for fingerprinting and diversity studies of pathogen isolates, as also recommended in a recent study in barley (Varshney et al. 2007). Nevertheless, in the case of higher numbers of SSR markers being available for a species, the most informative set of genome wide SSR markers can be selected based on repeat motif type and length as well as PIC values.

Higher resolution of dendrogram differentiation can be attributed to higher number of data points generated by AFLP as compared to SSR markers (Varshney et al. 2007). This is another reason why AFLP markers can be preferred over SSR markers for fingerprinting the isolates. In order to make the best interpretation of the genetic relationships of isolates, the genotyping data obtained using SSR and AFLP markers were combined and used for constructing the dendrogram. In this dendrogram, all the isolates were grouped into five major groups and three groups were further classified into subgroups. As a result, a total of 10 groups/subgroups were observed. Except for group IV, all the other groups/subgroups contained the majority of the isolates from the same geographical region. Geographical grouping of isolates has been observed in several earlier studies (Santra et al. 2001; Chongo et al. 2004). The specificity of the AFLP fragment or SSR alleles to certain $\mathrm{AB}$ isolates suggests the identification of geographical specific markers. While the SSR marker can be used as such to identify the location-specific isolates, the AFLP fragments can be sequenced and converted into locusspecific markers to identify region-specific $A B$ isolates. Indeed such a region-specific marker (RAPD fragment) to Indian AB isolates was identified by Santra et al. (2001).

As the dendrogram could group the majority of the isolates into region-specific subgroups/groups, all AFLP loci and SSR allelic data were inspected to determine the region-specific loci/alleles. The region-specific loci/alleles were present in $32-58 \%$ of the isolates examined (data not shown). In fact, the isolates coming from Hisar (all the four single spore isolates of AB4_HIS and AB18_HIS) and Sriganganagar (AB27_GAN) showed the presence of unique AFLP fragments (4) and SSR alleles (12). For instance, three AFLP primer pairs (E-TC/M-CAC, E-TC/ M-CAG and E-TG/M-CTG) showed the presence and one AFLP primer pair (E-AG/M-CTA) showed the absence of a unique band in all the singe spore isolates from these regions. Similarly, unique alleles detected at 11 SSR loci (ArA02T, $A r \mathrm{~A} 06 \mathrm{~T}, A r \mathrm{~A} 08 \mathrm{~T}, A r \mathrm{H} 02 \mathrm{~T} A r \mathrm{H} 04 \mathrm{~T}, A r \mathrm{H} 05 \mathrm{~T}$, $A r \mathrm{~S} 03 \mathrm{~T}, A r \mathrm{H} 07 \mathrm{D}, A r \mathrm{H} 08 \mathrm{D}, A r \mathrm{H} 11 \mathrm{D}$ and $A r \mathrm{R} 12 \mathrm{D})$ were restricted to all the 12 single spore isolates from Hisar (8 isolates) and Sriganganagar (4 isolates). The occurrence of unique locus (AFLP) or allele (SSR) in the isolates from Hisar (AB4_HIS, AB18_HIS) and Sriganganagar (AB27_HIS) can be explained by the transmission of the isolates between Hisar and Sriganganagar through air dispersion or exchange of chickpea seeds, as the distance between these two places is only $245 \mathrm{~km}$. Although the distance between Sriganganagar and Abohar is less than that of Sriganganagar and Hisar, the isolates from Abohar region neither shared the uniqueness of the $\mathrm{AB}$ isolates from Sriganganagar nor from Hisar, which supports the dispersal of $A B$ strains through the exchange of chickpea seeds instead of air dispersal between Sriganganagar 
(Rajasthan state) and Hisar (Haryana state) and not between Sriganganagar/Hisar and Abohar (Punjab state).

In terms of region-specific alleles among the isolates, one SSR marker $A r \mathrm{H} 02 \mathrm{~T}$ showed the unique allele for the isolates of Sundernagar (AB14) and one SSR marker $A r \mathrm{H} 06 \mathrm{~T}$ detected the unique allele for the isolates of Gurdaspur (AB1 and AB27). The uniqueness of the SSR alleles to these isolates probably indicates that there has not been an exchange of chickpea seeds from these places (remote locations in the Himachal Pradesh and Punjab states) to other places. These markers can be used as diagnostic markers to identify a region-specific isolate from a group of isolates.

Insights into the structure of Aschochyta rabiei populations will prove to be valuable in enhancing our understanding of the biology of Ascochyta blight epidemics and potentially adaptive genotypic diversity in the species. Model-based population structure analysis revealed four distinct groups or populations. The isolates of group $1 \mathrm{did}$ not show any admixture, suggesting the gene flow is currently limited among these populations although the isolates from Rajasthan and Haryana are separated by a short geographic distance. However, the other three groups were found to possess a varying degree of admixture percent of the alleles among these populations. Among 8 isolates studied from Rajasthan, 4 isolates were in group 1 (with no admixture), 3 isolates were in group 4 (with very low admixture) and interestingly only one isolate (AB26_GAN_4) from Rajasthan was found in group 3 (with high admixture percent with group 4). These differences in population structure among isolates within the same species and geographic regions are likely related to differences in evolutionary history and ecology. Of 16 isolates in group 2,11 isolates $(68.7 \%)$ were found to share common ancestry/alleles from group 3 and group 4 . However, only two isolates (AB12_ABO_4 and AB1_GUR_2) were found to share very low admixture of alleles with group 3. Similarly $10(47.6 \%)$ of 21 isolates in group 3 shared ancestry/alleles with group 2 and group 3 . In group 4, seven isolates (46.7\%) shared ancestry with group 2 and group 3.

In summary, the present study demonstrated the utility of both AFLP and SSR markers for assessing the molecular diversity in AB isolates. While SSR markers are very useful in providing the locus-specific marker and can be used to identify the region-specific isolates, the AFLP markers provide genome-wide profiling of the pathogen. A moderate level of genetic variability was observed in the $\mathrm{AB}$ isolates of the NWPZ of India. The combination of this genetic variability and potential for sexual recombination increases the likelihood that rare pathotypes may quickly increase and overcome new sources of resistance in chickpea as they are developed. This potential is further facilitated due to dispersal of pathogen by airborne ascospores. Therefore, it is recommended to monitor changes in the pathogen population to anticipate the breakdown of resistance in existing chickpea cultivars in India.

Acknowledgements This work, in part, was supported by Generation Challenge Programme (http://www.generationcp.org). Thanks are due to $\mathrm{Mr}$ A. Gafoor, Research Technician, for his help in some experiments.

\section{References}

Ambardar VK, Singh SK (1996) Identification and elucidation of Ascochyta rabiei isolates of chickpea in Jammu. Indian J Mycol Plant Pathol 26:4-8

Anderson JA, Churchill GA, Autrique JE, Tanksley SD, Sorrels ME (1993) Optimizing parental selection for genetic linkage maps. Genome 36:181-186. doi:10.1139/g93-024

Barve MP, Santra DK, Ranjekar PK, Gupta VS (2004) Genetic diversity analysis of a world-wide collection of Ascochyta rabiei isolates using sequence tagged microsatellite marker. World $\mathrm{J}$ Microb Biot 20:735-741. doi:10.1007/s11274-004-1550-8

Basandrai AK, Pande S, Kishore GK, Crouch JH, Basandrai D (2005) Cultural, morphological and pathological variation in Indian isolates of Ascochyta rabiei, the chickpea blight pathogen. Plant Pathol J 21:207-213

Chongo G, Gossen BD, Buckwaldt L, Adhikari T, Rimmer SR (2004) Genetic diversity of Ascochyta rabiei in Canada. Plant Dis 88:4 10. doi:10.1094/PDIS.2004.88.1.4

Cuc LM, Mace ES, Crouch JH, Quang VD, Long TD, Varshney RK (2008) Isolation and characterization of novel microsatellite markers and their application for diversity assessment in cultivated groundnut (Arachis hypogaea). BMC Plant Biol 8:55. doi:10.1186/1471-2229-8-55

Geistlinger J, Maqbool S, Kaiser WJ, Kahl G (1997) Detection of microsatellite fingerprint markers and their Mendelian inheritance in Ascochyta rabiei. Mycol Res 101:1113-1121. doi:10.1017/S0953756297004231

Geistlinger J, Weising K, Winter P, Kahl G (2000) Locus-specific microsatellite markers for the fungal chickpea pathogen Didymella rabiei (anamorph) Ascochyta rabiei. Mol Ecol 9:19391941. doi:10.1046/j.1365-294x.2000.01092-13.x

Gowen SR, Orton M, Thurley B, White A (1989) Variation in pathogenicity of Ascochyta rabiei on chickpeas. Trop Pest Manage 35:180-186. doi:10.1080/09670878909371353

Gupta PK, Varshney RK (2000) The development and use of microsatellite markers for genetic analysis and plant breeding with emphasis on bread wheat. Euphytica 113:163-185. doi:10.1023/A:1003910819967

Huson DH, Richter DC, Rausch C, Dezulian T, Franz M, Rupp R (2007) Dendroscope: An interactive viewer for large phylogenetic trees. BMC Bioinformatics 8:460. doi:10.1186/1471-2105$8-460$

Jamil JJ, Sarwar N, Sarwar M, Khan JA, Geistlinger J, Kahl G (2000) Genetic and pathogenic diversity within Ascochyta rabiei (Pass.) Lab. population in Pakistan causing blight of chickpea (Cicer arietinum). . Physiol Mol Plant Pathol 57:243-254. doi:10.1006/ pmpp. 2000.0303

Morjane H, Geistlinger J, Harrabi M, Weising K, Kahl G (1994) Oligonucleotide fingerprinting detects genetic diversity among Ascochyta rabiei isolates from a single chickpea field in Tunisia. Curr Genet 26:191-197. doi:10.1007/BF00309547 
Nei M (1972) Genetic distance between populations. Amer Naturalist 106:283-292. doi:10.1086/282771

Nene YL (1984) A review of Ascochyta blight of chickpea (Cicer arietinum L.). In: Saxena MC, Singh KB (eds) Ascochyta blight and winter sowing of chickpea. Proceedings of the Workshop on Ascochyta Blight and Winter Sowing of Chickpeas. Junk, The Hague, The Netherlands, pp 17-34

Pande S, Siddique KHM, Kishore GK, Baaya B, Gaur PM, Gowda CLL, Bretag T, Crouch JH (2005) Ascochyta blight of chickpea (Cicer arietinum L.): a review of biology, pathogenicity, and disease management. Aust J Agric Res 56:317-332. doi:10.1071/AR04143

Peever TL, Salimath SS, Su G, Kaiser WJ, Muehlbauer FJ (2004) Historical and contemporary multilocus population structure of Ascochyta rabiei (teleomorph: Didymella rabiei) in the Pacific Northwest of the United States. Mol Ecol 13:291-309. doi:10.1046/j.1365-294X.2003.02059.x

Powell W, Margenta M, Andre C, Hanfrey M, Vogel J, Tingey S, Rafalsky A (1996) The utility of RFLP, RAPD, AFLP and SSR (microsatellite) markers for germplasm analysis. Mol Breed 2:225-238. doi:10.1007/BF00564200

Pritchard JK, Stephens M, Donnelly P (2000) Inference of population structure using multilocus genotype data. Genetics 155:945-959

Punithalingam E, Holliday P (1972) Ascochyta rabiei. In Descriptions of pathogenic fungi and bacteria. Commonwealth Mycological Institute: Kew, England. Vol 34 p 337

Roldán-Ruiz I, Dendauw J, Van Bockstæle E, Depicker A, DeLoose M (2000) AFLP markers reveal high polymorphic rates in ryegrasses (Lolium spp.). Mol Breed 6:125-134. doi:10.1023/ A:1009680614564

Santra DK, Singh G, Kaiser WJ, Gupta VS, Ranjekar PK, Muehlbauer FJ (2001) Molecular analysis of Ascochyta rabiei (Pass.) Labr., the pathogen of ascochyta blight in chickpea. Theor Appl Genet 102:676-682. doi:10.1007/s001220051696

Singh KB, Reddy MV (1991) Advances in disease-resistance breeding in chickpea. Adv Agron 45:191-222. doi:10.1016/S0065-2113 (08)60041-3
Singh KB, Reddy MV (1996) Improving chickpea yield by incorporating resistance to Ascochyta blight. Theor Appl Genet 92:509515. doi:10.1007/BF00224552

Spooner DM, Tivang J, Nienhuis J, Miller JT, Douches DS, Contreras MA (1996) Comparison of four molecular markers in measuring relationships among the wild potato relatives Solanum section Etuberosum (subgenus Potatoe). Theor Appl Genet 92:532-540. doi:10.1007/BF00224555

Swofford DL (1998) PAUP*. Phylogenetic Analysis Using Parsimony (*and Other Methods). Version 4. Sinauer Associates, Sunderland, Massachusetts

Tegelstrom H (1992) Detection of mitochondrial DNA fragments. In: Hoelzel AR (ed) Molecular genetic analysis of populations: a practical approach. IRL Press, Oxford, pp 89-114

Udupa SM, Weigand F, Saxena MC, Kahl G (1998) Genotyping with RAPD and microsatellite markers resolves pathotype diversity in the ascochyta blight pathogen of chickpea. Theor Appl Genet 97:299-307. doi:10.1007/s001220050899

Varshney RK, Chabane K, Hendre PS, Aggarwal RK, Graner A (2007) Comparative assessment of EST-SSR, EST-SNP and AFLP markers for evaluation of genetic diversity and conservation of genetic resources using wild, cultivated and elite barleys. Plant Sci 173:638-649. doi:10.1016/j. plantsci.2007.08.010

Vos P, Hogers R, Bleeker M, Reijans M, Lee T, Hornes M, Friters A, Pot J, Paleman J, Kuiper M, Zabeau M (1995) AFLP: a new technique for DNA fingerprinting. Nucleic Acids Res 23:44074414. doi:10.1093/nar/23.21.4407

Weising K, Kaemmer D, Epplen JT, Weigand F, Saxena MC, Kahl G (1991) DNA fingerprinting of Ascochyta rabiei with synthetic oligodeoxynucleotides. Curr Genet 19:483-489. doi:10.1007/ BF00312740

Williams JGK, Kubelik AR, Livak KJ, Rafalski JA, Tingey SV (1990) DNA polymorphisms amplified by arbitrary primers are useful as genetic markers. Nucleic Acids Res 18:6531-6535. doi:10.1093/ nar/18.22.6531 